\title{
Evaluation of the Low Corrosion Resistant Phase Formed During the Sigma Phase Precipitation in Duplex Stainless Steels
}

\author{
Darlene Yuko Kobayashi ${ }^{\mathrm{a}}$, Stephan Wolynec ${ }^{* \mathrm{~b}}$ \\ ${ }^{\mathrm{a}}$ Centro Tecnológico da Marinha em São Paulo, 05598-900 São Paulo - SP, Brazil \\ ${ }^{\mathrm{b}}$ Departamento de Engenharia Metalúrgica e de Materiais, Escola Politécnica da \\ Universidade de São Paulo, 05508-900 São Paulo - SP, Brazil
}

Received: March 19, 1999; Revised: July 5, 1999

\begin{abstract}
The duplex stainless steels, having a volumetric fraction of $50 \%$ ferrite and $50 \%$ austenite, conciliate high corrosion resistance with good mechanical properties. But, in many circumstances different phase transformations may occur, such as that responsible for sigma phase precipitation, which make the steel susceptible to localized corrosion. During the sigma phase precipitation a new austenitic phase is formed with a very low corrosion resistance. In the present research the composition of this new austenitic phase was evaluated in four duplex stainless steels, with different $\mathrm{Mo}, \mathrm{N}$ and $\mathrm{Cu}$ contents. After the solution anneal at $1050{ }^{\circ} \mathrm{C}$, samples of these steels were aged at $850^{\circ} \mathrm{C}$ during $1 \mathrm{~h}$ and $5 \mathrm{~h}$ for sigma phase precipitation. Using the ferritoscope and an image analyzer it was possible to determine the volumetric fractions of ferrite and sigma phase, respectively, while those of austenite and the new austenitic phase were determined by difference to $100 \%$ volume. Finally, by using mass balance it was possible to determine theoretically the composition of the new austenitic phase. This phase is poor in $\mathrm{Cr}$ and Mo free, which explains its poor corrosion resistance.
\end{abstract}

Keywords: duplex stainless steels, sigma phase, selective corrosion, localized corrosion

\section{Introduction}

The duplex stainless steels are $\mathrm{Fe}-\mathrm{Cr}-\mathrm{Ni}$ alloys presenting an approximate volumetric fraction of $50 \%$ ferrite $(\alpha)$ and $50 \%$ austenite $(\gamma)$ in their microstructure. Their main feature is that they compromise the favorable corrosion resistance of the austenitic stainless steels with good mechanical properties.

Notwithstanding these advantages, duplex stainless steels are susceptible to the precipitation of additional phases that affect both the corrosion and the mechanical properties. These phases may be formed during the solidification of the alloy or in the subsequent heat treatments or plastic deformation processes, or even due to the aging processes during its use, causing a marked effect upon the workability and the useful life of the material. One of the possible phases to be formed is the sigma phase, a hard and brittle intermetallic compound, rich in $\mathrm{Cr}$ and $\mathrm{Mo}$, which is formed from the ferrite.

The sigma phase in stainless steels is an intermetallic compound, non-magnetic ${ }^{1,2}$, with a complex tetragonal structure, and when present has deleterious effects upon both the mechanical and the corrosion properties ${ }^{3}$.

*e-mail: swolynec@usp.br
Bain and Griffth ${ }^{1}$ first detected this phase in 1927, during their systematic investigation of $\mathrm{Fe}-\mathrm{Cr}-\mathrm{Ni}$ alloys. They found, in certain composition ranges, the presence of a hard and brittle phase, which was responsible for the sample fracture during the hardness testing.

In most of the duplex stainless steels this phase contains $\mathrm{Fe}, \mathrm{Cr}$ and $\mathrm{Mo}$, and it is formed between $600^{\circ} \mathrm{C}$ and $950^{\circ} \mathrm{C}$, its precipitation being faster between $700{ }^{\circ} \mathrm{C}$ and $900^{\circ} \mathrm{C}$. The embrittlement of some alloys due to the sigma phase precipitation may occur in very short times, of the order of $3 \min ^{2,4}$.

Brandi and Padilha ${ }^{5}$ and Maehara et al. ${ }^{6}$ found during the sigma phase precipitation in duplex stainless steels that as the amount of sigma phase increases the amount of ferrite decreases, until its total consumption. From this it was concluded that the sigma phase is formed from the ferrite. The proposed mechanism for this formation ${ }^{5,6}$ is the euctetoid decomposition of ferrite according to the reaction:

ferrite $\rightarrow$ sigma + austenite

There is a consensus between several researchers ${ }^{4-9}$ that the sigma phase nucleation takes place at the austenite/ferrite interface and then grows towards the ferrite. 
Brandi and Padilha ${ }^{5}$ and Barbosa et $a .^{7}$ found that initially the sigma phase precipitates as a film, forming a halo at the austenite/ferrite interface. At temperatures of the order of $700{ }^{\circ} \mathrm{C}$ to $800{ }^{\circ} \mathrm{C}$, this film becomes thicker until an austenite formation at the growing front occurs, allowing the cooperation for the lamellar euctetoid growth. For higher temperatures the setting of a cooperative growth is more difficult, because this would imply in the consumption of the thermodynamic potential to form the sigma/austenite interface. Moreover, at higher temperatures the atoms can diffuse to larger distances, which would favor the formation of a massive sigma phase, that is, of a divorced euctetoid ${ }^{7}$.

The sigma phase growth from ferrite instead of austenite occurs because the sigma phase is rich in ferritizing elements and the diffusion in ferrite is faster than in austenite ${ }^{5}$.

The harmful effect of sigma phase upon corrosion resistance of duplex stainless steels was reported in several works ${ }^{10-22}$. This effect has been evaluated through different tests, such as general corrosion tests ${ }^{12}$, pitting potential tests $^{12,14,15,17,19}$, crevice corrosion tests ${ }^{17}$, intergranular corrosion tests ${ }^{16,18-20}$ and stress corrosion tests ${ }^{15}$. Moreover, this effect has been of great concern in welding of duplex stainless steels, because during this process the sigma phase is formed in the heat affected zones (HAZ) ${ }^{13,21,22}$. Leaks in pipelines produced with this type of steel were reported to occur in these zones ${ }^{21}$.

According to Truman and Pirt ${ }^{11}$ this effect is a consequence of chromium and molybdenum content decrease in the matrix phases, because the sigma phase is considerably richer in these elements than either the ferrite or austenite. Adhe et al. ${ }^{19}$ proposed that this decrease is confined to regions adjacent to sigma phase. Wilms et al. ${ }^{17}$, on the other hand, observed that the localized corrosion starts next to the sigma phase in the newly formed secondary austenite.

Although the sigma phase has been considered extremely harmful to the corrosion resistance of the duplex stainless steels, the available information about its magnitude and extent is limited. Thus, it was decided to undertake a detailed investigation of the influence that the presence of this phase in four different duplex stainless steels has upon their microstructure and the chemical composition of phases, and on how these parameters are related to the corrosion of these materials in a $3.5 \% \mathrm{NaCl}$ solution.

\section{Materials and Methods}

In present research the following duplex stainless steels were investigated: 3RE60 (UNS S31500), AV2205 (UNS S31803), UR50 (UNS S32404) and UR45N. The testing samples were removed from $3 \mathrm{~mm}$ to $6 \mathrm{~mm}$ thick rolled sheets. The chemical composition of these steels, supplied by the manufacturer, is given in Table 1.

All materials were submitted to solution anneal at $1050{ }^{\circ} \mathrm{C}$ for $30 \mathrm{~min}$, followed by cooling in water. After this they were submitted to a heat treatment at $850{ }^{\circ} \mathrm{C}$ for 1 $\mathrm{h}$ and $5 \mathrm{~h}$, with the purpose to precipitate the sigma phase.

The corrosion resistance of these steels was evaluated by cyclic potentiodynamic polarization curves in order to measure their pitting potential and to identify the possible nucleation sites of the pits. These tests were performed at room temperature in a $3,5 \% \mathrm{NaCl}$ aqueous solution, with a scanning rate of $1 \mathrm{mV} / \mathrm{s}$ started $5 \mathrm{~min}$ after the immersion of the sample inside the solution. In the testing cell, with a 700-mL capacity, a graphite counter electrode and a saturated calomel reference electrode (SCE) were used. The testing samples were submitted to two different surface finishes, namely:

- abrasion with silicon carbide paper to the grade 600 for pitting corrosion determination, and

- polishing with diamond paste to the grade $1 \mu \mathrm{m}$ for preferential corrosion sites determination with the scanning electron microscope (SEM).

At the SEM both the primary and the secondary electron images were determined. The first, which are more sensitive to the nature of the existing elements, were used to identify the different phases in the samples, while the latter, which are more sensitive to the topography of the surface, were used to observe the corrosion morphology.

The individual phases were analyzed with an energy dispersion system (EDS) coupled to the SEM, displaying an analytical beam diameter of about $5 \mu \mathrm{m}$. This implies that the analysis of phases with sizes smaller than this value is unreliable.

The volumetric percentage of $\alpha$ phase was measured with a ferritoscope. Since there are only two phases in the investigated alloys, the volumetric percentage of $\gamma$ phase was determined by difference between $100 \%$ and the volumetric percentage of the $\alpha$ phase.

After the heat treatment the alloys presented three phases: ferrite $(\alpha)$, sigma $(\sigma)$ and austenite $(\gamma)$. The $\gamma$ phase

Table 1. Chemical composition of investigated alloys (in wt.\%).

\begin{tabular}{lcccccccccccc}
\hline Alloys & $\mathrm{Cr}$ & $\mathrm{Ni}$ & $\mathrm{Mo}$ & $\mathrm{N}$ & $\mathrm{Cu}$ & $\mathrm{Mn}$ & $\mathrm{Si}$ & $\mathrm{C}$ & $\mathrm{P}$ & $\mathrm{S}$ \\
\hline UR45N & 22.52 & 5.77 & 2.81 & 0.144 & 0.08 & 1.78 & 0.47 & 0.02 & 0.028 & 0.009 \\
UR50 & 22.35 & 6.10 & 2.78 & 0.083 & 1.06 & 1.33 & 0.61 & 0.025 & 0.030 & 0.008 \\
AV2205 & 21.93 & 5.65 & 3.17 & 0.188 & 0.13 & 1.48 & 0.48 & 0.03 & 0.020 & 0.008 \\
3RE60 & 18.40 & 5.01 & 2.78 & 0.086 & 0.08 & 1.56 & 1.60 & 0.03 & 0.027 & 0.010 \\
\hline
\end{tabular}


can be divided in two: the one that was originally present in the alloy, that will be named as initial austenite $\left(\gamma_{\text {in }}\right)$, and the austenite provided by the euctetoid decomposition of ferrite [Eq. (1)], that will be named as new austenite $\left(\gamma_{\text {new }}\right)$. In order to make easier the data handling, the $\alpha$ phase in the solution annealed alloy will be named as initial ferrite $\left(\alpha_{\text {in }}\right)$ and after the heat treatment as final ferrite $\left(\alpha_{\text {final }}\right)$.

The amount of each of the above phases was obtained as follows:

- final ferrite $\left(\alpha_{\text {final }}\right)$ : measured with the ferritoscope;

- sigma $(\sigma)$ : measured with an image analyzer (quantitative metallography);

- austenite $\left(\gamma_{\text {in }}\right.$ and $\left.\gamma_{\text {new }}\right)$ : the amount of $\gamma_{\text {in }}$ is that of the austenite in the solution annealed alloy; the amount of $\gamma_{\text {new }}$ was calculated using the following relationship:

$$
\% \gamma_{\text {in }}+\% \gamma_{\text {new }}+\% \alpha_{\text {final }}+\% \sigma=100 \%
$$

where $\% \gamma_{\text {in }}, \% \gamma_{\text {new }}, \% \alpha_{\text {final }}$ and $\% \sigma$ are the volumetric percentages of the respective phases. In the above equation all terms are known with the exception of $\% \gamma_{\text {new }}$, so that:

$$
\% \gamma_{\text {new }}=100 \%-\left(\% \gamma_{\text {in }}+\% \alpha_{\text {final }}+\% \sigma\right)
$$

\section{Results}

\subsection{Microstructure of the alloys}

The Fig. 1 is a micrograph of the AV2205 alloy, after solution anneal at $1050{ }^{\circ} \mathrm{C}$ during $30 \mathrm{~min}$. This micrograph is typical of all the other investigated alloys, where the clearer phase is the austenite and the darker phase is the ferrite. It is observed that both austenite and ferrite form lamellar like microstructure, which was confirmed by examining the other two orthogonal planes to that shown in Fig. 1.

The Fig. 2 shows the microstructure of the same alloy after the heat treatment at $850{ }^{\circ} \mathrm{C}$ during $1 \mathrm{~h}$; on it the

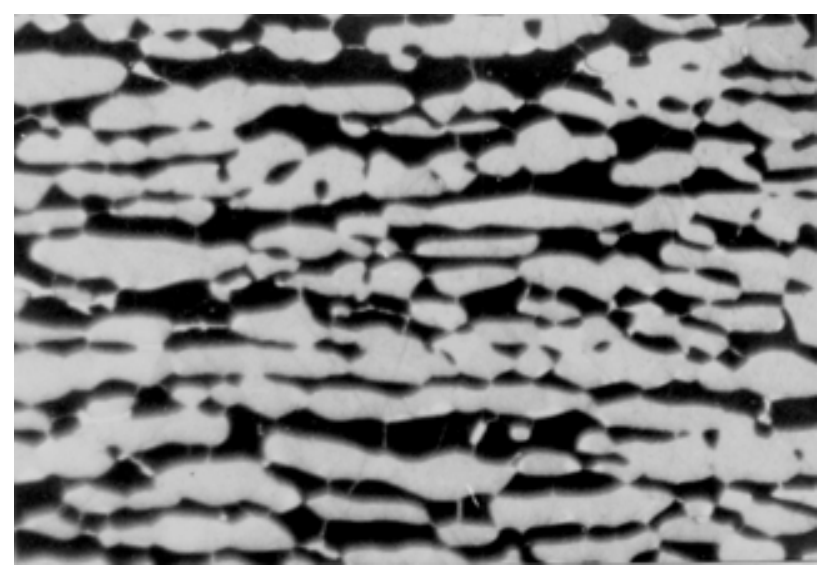

Figure 1. Microstructure of the AV2205 alloy solution annealed at $1050^{\circ} \mathrm{C}$ for $30 \mathrm{~min}$. Clear: austenite; dark: ferrite. $811 \mathrm{X}$. austenite is the largest continuous gray phase, the ferrite is the dispersed gray phase and the sigma is the white phase. It is noticed that:

- the sigma phase has predominantly a massive structure, it nucleates at the austenite/ferrite interface and grows inside the ferrite, occupying its space;

- the new austenite $\left(\gamma_{\text {new }}\right)$, originated from the euctetoid decomposition, is not identified at the micrograph.

The increase of the heat treatment time to $5 \mathrm{~h}$ increases the sigma phase content, but does not alter the general feature of the microstructure.

The volumetric percentages of all phases, determined by the described methods, are given in Tables 2 to 4 . It is verified that in the solution annealed alloys the austenite and ferrite contents are close do $50 \%$, and that after the sigma phase precipitation there is a decrease of ferrite content and the formation of a small amount of $\gamma_{\text {new }}$.

\subsection{Chemical composition}

After the volumetric percentage measurement, the chemical composition of different phases was determined with the EDS technique. The results are given in Tables 5 to 7 . The sigma phase was only analyzed in the alloy heat treated at $850{ }^{\circ} \mathrm{C}$ during $5 \mathrm{~h}$ due to its larger

Table 2. The volumetric percentages of $\gamma$ and $\alpha$ phases in the solution annealed alloys.

\begin{tabular}{lcc}
\hline \multirow{2}{*}{ Alloys } & \multicolumn{2}{c}{ Volumetric percentage $(\%)$} \\
\cline { 2 - 3 } & $\gamma$ phase & $\alpha$ phase \\
\hline AV2205 & $59.5 \pm 1.0$ & $40.5 \pm 1.0$ \\
UR45N & $50.7 \pm 3.6$ & $49.3 \pm 3.6$ \\
UR50 & $50.1 \pm 3.7$ & $49.9 \pm 3.7$ \\
3RE60 & $55.0 \pm 1.0$ & $45.0 \pm 1.0$ \\
\hline
\end{tabular}

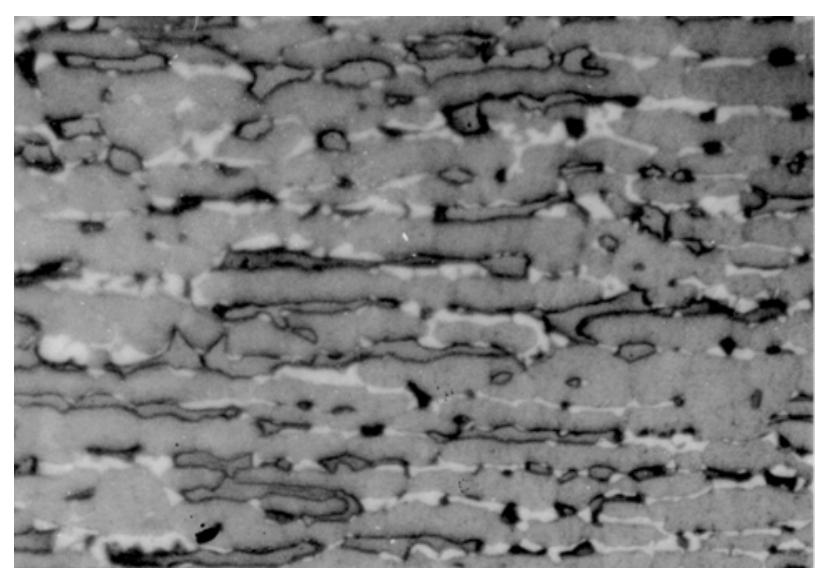

Figure 2. Microstructure of the AV2205 alloy after heat treatment at $850{ }^{\circ} \mathrm{C}$ for $1 \mathrm{~h}$. White: sigma phase; continuous gray: austenite; dispersed gray: ferrite. $811 \mathrm{X}$. 
Table 3. The volumetric percentages of $\gamma_{i n}, \gamma_{\text {new }}, \alpha_{\text {final }}$ and $\sigma$ phases in the alloys heat-treated for $1 \mathrm{~h}$.

\begin{tabular}{lcccc}
\hline \multirow{2}{*}{ Alloys } & \multicolumn{4}{c}{ Volumetric percentage (\%) } \\
\cline { 2 - 5 } & $\gamma_{\text {in }}$ & $\gamma_{\text {new }}$ & $\alpha_{\text {final }}$ & $\sigma$ \\
\hline AV2205 & $59.5 \pm 1.0$ & $5.5 \pm 1.5$ & $14.0 \pm 1.0$ & $21,0 \pm 0.4$ \\
UR45N & $50.7 \pm 3.6$ & $5.7 \pm 7.4$ & $15.0 \pm 0.8$ & $28,6 \pm 6.5$ \\
UR50 & $50.1 \pm 3.7$ & $3.8 \pm 3.8$ & $10.8 \pm 0.5$ & $35,3 \pm 0.9$ \\
3RE60 & $55.0 \pm 1.0$ & $2.5 \pm 1.5$ & $32.7 \pm 0.6$ & $9,8 \pm 0.9$ \\
\hline
\end{tabular}

Table 4. The volumetric percentages of $\gamma_{\text {in }}, \gamma_{\text {new }}, \alpha_{\text {final }}$ and $\sigma$ phases in the alloys heat-treated for $5 \mathrm{~h}$.

\begin{tabular}{lcccc}
\hline \multirow{2}{*}{ Alloys } & \multicolumn{4}{c}{ Volumetric percentage $(\%)$} \\
\cline { 2 - 5 } & $\gamma_{\text {in }}$ & $\gamma_{\text {new }}$ & $\alpha_{\text {final }}$ & $\sigma$ \\
\hline AV2205 & $59.5 \pm 1.0$ & $5.8 \pm 1.6$ & $2.5 \pm 0.7$ & $32.2 \pm 1.1$ \\
UR45N & $50.7 \pm 3.6$ & $2.7 \pm 3.6$ & $8.3 \pm 0.3$ & $38.3 \pm 0.2$ \\
UR50 & $50.1 \pm 3.7$ & $1.8 \pm 3.7$ & $3.0 \pm 0.3$ & $45.1 \pm 0.4$ \\
3RE60 & $55.0 \pm 1.0$ & $4.4 \pm 1.2$ & $27.7 \pm 0.5$ & $12.9 \pm 0.5$ \\
\hline
\end{tabular}

volumetric fraction and consequently smaller measuring error.

\subsection{Determination of chemical composition of the new austenite}

Since the new austenite $\left(\gamma_{\text {new }}\right)$ was not microscopically detected, it may be admitted that it has precipitated adjacent to the already existing austenite, while the sigma has grown as a separate phase inside the ferrite.

The austenite precipitated in higher temperatures may be admitted then as a film between the sigma phase and the original austenite. This explains why its composition is impossible to determine, because the EDS analytical beam has a diameter of about $5 \mu \mathrm{m}$, which is about half of the original austenite lamella width. Thus, any attempt to analyze this new phase will give the composition of the original austenite.

The chemical composition of the new austenite was then calculated theoretically, using the mass balance. This was possible because the volumetric percentages of all phases are known, as well as their chemical compositions with the exception of that of new austenite. The steps followed in order to perform the calculations are exemplified for the alloy AV2205 heat treated at $850{ }^{\circ} \mathrm{C}$ for $1 \mathrm{~h}$. The Table 8 displays for this alloy the amount of existing phases under real conditions and, in order to make easier the reasoning, under the supposition that the alloy is $100 \%$ ferritic.

In order to determine the composition of the new austenite, it was assumed that the mass of the initial ferrite was $30 \mathrm{~g}$ and its volume and the mass of the remaining phases were calculated as follows:

$$
\mathrm{V}_{\alpha \text { in }}=\frac{\mathrm{M}_{\alpha \text { in }}}{\mathrm{D}_{\alpha}}
$$

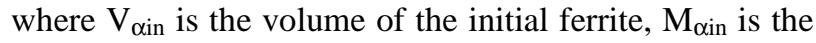
mass of the initial ferrite and D is the density of ferrite. Since* $\mathrm{D}=7.9 \mathrm{~g} / \mathrm{cm}^{3}$, it follows:

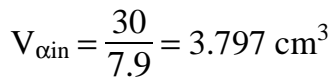

The mass of the final ferrite $\mathrm{M}_{\alpha \text { final }}$ will be then:

$$
\begin{aligned}
& M_{\alpha \text { final }}=V_{\alpha \text { final }} D_{\alpha}=0.346 V_{\alpha \text { in }} D_{\alpha} \\
& M_{\alpha \text { final }}=0.346 \times 3.797 \times 7.9=10.4 \mathrm{~g}
\end{aligned}
$$

Table 5. The chemical composition of $\gamma$ and $\alpha$ phases in the solution annealed alloys.

\begin{tabular}{lcccccccc}
\hline \multirow{2}{*}{ Alloys } & Phase & \multicolumn{7}{c}{ Elements (wt \%) } \\
\cline { 3 - 9 } & & $\mathrm{Fe}$ & $\mathrm{Cr}$ & $\mathrm{Ni}$ & $\mathrm{Mo}$ & $\mathrm{Cu}$ & $\mathrm{Mn}$ & $\mathrm{Si}$ \\
\hline \multirow{2}{*}{ AV2205 } & $\alpha$ & 64.10 & 25.52 & 4.05 & 4.10 & 0.10 & 1.54 & 0.59 \\
& $\gamma$ & 66.18 & 22.14 & 6.41 & 2.65 & 0.32 & 1.81 & 0.50 \\
\hline \multirow{2}{*}{ UR45N } & $\alpha$ & 64.06 & 26.02 & 4.08 & 3.48 & 0.09 & 1.75 & 0.51 \\
& $\gamma$ & 66.38 & 21.71 & 6.91 & 2.21 & 0.08 & 2.19 & 0.52 \\
\hline \multirow{2}{*}{ UR50 } & $\alpha$ & 62.85 & 26.26 & 4.37 & 3.52 & 0.97 & 1.37 & 0.67 \\
& $\gamma$ & 65.19 & 21.44 & 7.29 & 2.16 & 1.67 & 1.60 & 0.65 \\
\hline \multirow{2}{*}{$3 R$ 600 } & $\alpha$ & 67.98 & 21.51 & 3.46 & 3.44 & 0.06 & 1.70 & 1.84 \\
& $\gamma$ & 69.74 & 18.67 & 5.70 & 2.14 & 0.24 & 1.95 & 1.56 \\
\hline
\end{tabular}

* It was assumed that the density of ferrite is equal to the density of a ferritic stainless steel having a composition similar to this phase $^{13}$. 
Table 6. Chemical composition of $\alpha$ and $\gamma$ phases in the alloys heat-treated at $850{ }^{\circ} \mathrm{C}$ for $1 \mathrm{~h}$.

\begin{tabular}{lcccccccc}
\hline \multirow{2}{*}{ Alloys } & Phase & \multicolumn{7}{c}{ Elements(wt\%) } \\
\cline { 3 - 9 } & & $\mathrm{Fe}$ & $\mathrm{Cr}$ & $\mathrm{Ni}$ & $\mathrm{Mo}$ & $\mathrm{Cu}$ & $\mathrm{Mn}$ & $\mathrm{Si}$ \\
\hline \multirow{2}{*}{ AV2205 } & $\alpha$ & 66.91 & 25.22 & 2.60 & 2.56 & 0.19 & 1.47 & 0.51 \\
& $\gamma$ & 66.41 & 21.93 & 6.42 & 2.56 & 0.25 & 1.91 & 0.53 \\
\hline \multirow{2}{*}{ UR45N } & $\alpha$ & 65.89 & 26.44 & 3.02 & 2.25 & 0.07 & 1.80 & 0.55 \\
& $\gamma$ & 65.77 & 22.00 & 7.23 & 2.12 & 0.20 & 2.21 & 0.51 \\
\hline \multirow{2}{*}{ UR50 } & $\alpha$ & 65.92 & 26.43 & 2.64 & 1.77 & 1.11 & 1.40 & 0.62 \\
& $\gamma$ & 65.39 & 21.23 & 7.48 & 2.02 & 1.65 & 1.66 & 0.58 \\
\hline \multirow{2}{*}{3 RE60 } & $\alpha$ & 68.67 & 22.16 & 2.94 & 2.59 & 0.13 & 1.69 & 1.84 \\
& $\gamma$ & 69.90 & 18.59 & 5.68 & 2.16 & 0.20 & 1.87 & 1.60 \\
\hline
\end{tabular}

Table 7. Chemical composition of $\alpha, \gamma$ and $\sigma$ phases in the alloys heat-treated at $850{ }^{\circ} \mathrm{C}$ for $5 \mathrm{~h}$.

\begin{tabular}{|c|c|c|c|c|c|c|c|c|}
\hline \multirow[t]{2}{*}{ Alloys } & \multirow[t]{2}{*}{ Phase } & \multicolumn{7}{|c|}{ Elements (wt\%) } \\
\hline & & $\mathrm{Fe}$ & $\mathrm{Cr}$ & $\mathrm{Ni}$ & Mo & $\mathrm{Cu}$ & $\mathrm{Mn}$ & $\mathrm{Si}$ \\
\hline \multirow[t]{3}{*}{ AV2205 } & $\alpha$ & 68.43 & 25.18 & 2.46 & 1.76 & 0.24 & 1.43 & 0.51 \\
\hline & $\gamma$ & 66.35 & 22.03 & 6.37 & 2.64 & 0.35 & 1.81 & 0.46 \\
\hline & $\sigma$ & 57.24 & 31.16 & 2.41 & 6.93 & 0.04 & 1.52 & 0.71 \\
\hline \multirow[t]{3}{*}{ UR45N } & $\alpha$ & 68.88 & 25.48 & 2.24 & 1.24 & 0.24 & 1.44 & 0.50 \\
\hline & $\gamma$ & 66.44 & 21.67 & 7.03 & 2.11 & 0.12 & 2.18 & 0.46 \\
\hline & $\sigma$ & 57.01 & 30.92 & 2.80 & 6.60 & 0.11 & 1.99 & 0.58 \\
\hline \multirow[t]{3}{*}{ UR50 } & $\alpha$ & 68.47 & 25.88 & 2.21 & 1.13 & 0.87 & 0.87 & 0.57 \\
\hline & $\gamma$ & 65.09 & 21.45 & 7.29 & 2.24 & 1.57 & 1.71 & 0.65 \\
\hline & $\sigma$ & 56.39 & 31.80 & 2.82 & 6.26 & 0.84 & 1.47 & 0.84 \\
\hline \multirow[t]{3}{*}{ 3RE60 } & $\alpha$ & 69.20 & 22.67 & 2.60 & 2.16 & 0.15 & 1.43 & 1.79 \\
\hline & $\gamma$ & 70.17 & 18.48 & 5.61 & 2.20 & 0.16 & 1.82 & 1.66 \\
\hline & $\sigma$ & 57.77 & 22.47 & 2.82 & 12.64 & 0.12 & 1.73 & 2.46 \\
\hline
\end{tabular}

Table 8. The volumetric percentage of the existing phases in alloy AV2205 heat-treated at $850^{\circ} \mathrm{C}$ for $1 \mathrm{~h}$, under real conditions and under the supposition that the alloy is $100 \%$ ferritic.

\begin{tabular}{|c|c|c|c|c|}
\hline & $\begin{array}{c}\text { Initial ferrite } \\
\left(\mathrm{V}_{\alpha i n}\right)\end{array}$ & $\begin{array}{c}\text { Final ferrite } \\
\left(\mathrm{V}_{\alpha \text { final }}\right)\end{array}$ & $\begin{array}{c}\text { Sigma } \\
\left(\mathrm{V}_{\sigma}\right)\end{array}$ & $\begin{array}{c}\text { New austenite } \\
\left(\mathrm{V}_{\gamma_{\text {new }}}\right)\end{array}$ \\
\hline vol \% & $40.5 \pm 1.0$ & $14.0 \pm 1.0$ & $21.0 \pm 0.4$ & $5.5 \pm 1.5$ \\
\hline vol \% & 100 & 34.6 & 51.9 & 13.6 \\
\hline
\end{tabular}

The mass of the new austenite $\mathbf{M}_{\gamma \text { new }}$ is given by:

$\mathrm{M}_{\gamma \text { new }}=\mathrm{V}_{\gamma \text { new }} \mathrm{D}_{\gamma \text { new }}=0.136 \mathrm{~V}_{\alpha \text { in }} \mathrm{D}_{\gamma \text { new }}$

Assuming that $\mathrm{D}_{\text {rnew }}=\mathrm{D}_{\alpha}$ it follows:

$\mathrm{M}_{\gamma \text { new }}=0.136 \times 3.797 \times 7.9=4.1 \mathrm{~g}$

Finally, the mass of the sigma phase $\mathrm{M}_{\sigma}$ can be determined by difference, that is:

$$
\mathrm{M}_{\sigma}=30.0-10.4-4.1=15.5 \mathrm{~g}
$$

With the above mass values and the chemical compositions given in Tables 5, 6 and 7 it is possible to calculate the mass of each chemical element in the initial ferrite, in the final ferrite and in the sigma phase. With these values the mass of each element in the new austenite can be 
Table 9. The chemical composition of the new austenite for alloys heat-treated at $850^{\circ} \mathrm{C}$ for $1 \mathrm{~h}$.

\begin{tabular}{lcccc}
\hline \multirow{2}{*}{ Elements } & \multicolumn{4}{c}{ Chemical composition (wt\%) } \\
\cline { 2 - 5 } & AV2205 & UR45N & UR50 & 3RE60 \\
\hline $\mathrm{Fe}$ & 80.51 & 86.95 & 81.57 & 80.68 \\
$\mathrm{Cr}$ & 3.85 & 0.31 & - & 7.53 \\
$\mathrm{Ni}$ & 13.49 & 12.21 & 16.90 & 10.41 \\
$\mathrm{Mo}$ & - & - & - & - \\
$\mathrm{Mn}$ & 1.75 & 0.38 & 0.25 & 1.39 \\
$\mathrm{Si}$ & 0.29 & 0.13 & - & - \\
$\mathrm{Cu}$ & 0.11 & 0.039 & 1.27 & - \\
\hline
\end{tabular}

Table 10. The chemical composition of the new austenite for alloys heat treated at $850{ }^{\circ} \mathrm{C}$ for $5 \mathrm{~h}$.

\begin{tabular}{lcccc}
\hline \multirow{2}{*}{ Elements } & \multicolumn{4}{c}{ Chemical composition (wt\%) } \\
\cline { 2 - 5 } & AV2205 & UR45N & UR50 & 3RE60 \\
\hline $\mathrm{Fe}$ & 86.31 & 84.13 & 82.34 & 77.77 \\
$\mathrm{Cr}$ & - & - & - & 9.82 \\
$\mathrm{Ni}$ & 11.91 & 15.72 & 12.82 & 9.27 \\
$\mathrm{Mo}$ & - & - & - & - \\
$\mathrm{Mn}$ & 1.46 & - & 3.39 & 2.86 \\
$\mathrm{Si}$ & - & 0.015 & - & 0.29 \\
$\mathrm{Cu}$ & 0.32 & - & 1.45 & - \\
\hline
\end{tabular}

calculated by undertaking a mass balance, as exemplified below for the iron element:

$$
M_{\frac{\mathrm{Fe}}{\gamma \text { new }}}=M_{\frac{\mathrm{Fe}}{\alpha \text { in }}}-\left(M_{\frac{\mathrm{Fe}}{\alpha \text { final }}}+M_{\frac{\mathrm{Fe}}{\sigma}}\right)
$$

where $\mathrm{M}_{\mathrm{Fe}}$ is the mass of iron in $\mathrm{g}$.

After the mass of each element was calculated, it was possible to determine the wt $\%$ chemical composition of the new austenite for all alloys, as presented in Tables 9 and 10 .

It was found that the new austenite has a very low or almost absent content of $\mathrm{Cr}$ and it has no Mo at all. In the

Table 11. The pitting potentials of alloys solution annealed and heattreated at $850^{\circ} \mathrm{C}$ for $1 \mathrm{~h}$ and $5 \mathrm{~h}$.

\begin{tabular}{lccc}
\hline \multirow{2}{*}{ Alloys } & \multicolumn{3}{c}{ Pitting potential (mV.SCE) } \\
\cline { 2 - 4 } & solution anneal & $850^{\circ} \mathrm{C} / 1 \mathrm{~h}$ & $850^{\circ} \mathrm{C} / 5 \mathrm{~h}$ \\
\hline AV2205 & $1034 \pm 40$ & $495 \pm 40$ & $329 \pm 26$ \\
UR45N & $1018 \pm 61$ & $418 \pm 48$ & $307 \pm 37$ \\
UR50 & $1045 \pm 29$ & $311 \pm 48$ & $210 \pm 82$ \\
3RE60 & $514 \pm 142$ & $303 \pm 63$ & $310 \pm 29$ \\
\hline
\end{tabular}

3RE60 alloy this phase has the largest $\mathrm{Cr}$ content, when compared to the other alloys, but it is much lower than that detected in the initial austenite.

\subsection{Pitting potential}

The pitting potentials were determined from polarization curves. They are given in Table 11; the pitting potential was considered as the one at which there is a sharp increase in the current density value.

Under the solution anneal conditions the AV2205, UR45N and UR50 alloys did show a high pitting potential, which implies a high corrosion resistance to this type of attack; the 3RE60 alloy, however, has a much lower pitting potential, implying in a lower resistance to this type of corrosion.

After the heat treatment at $850{ }^{\circ} \mathrm{C}$ there was a pronounced decrease in pitting potential values, as a direct consequence of the sigma phase precipitation. This may be better visualized in Fig. 3, in which the pitting potential of all alloys is plotted as a function of volumetric percentage of sigma phase.

\subsection{Corrosion morphology examination}

The Figs. 4 to 7 show the samples' surface after the potentiodynamic polarization tests. The AV2205, UR45N and UR50 solution annealed alloys displayed the same type of behavior, with very small pits, not larger than $30 \mu \mathrm{m}$, as that shown in Fig. 4 (secondary electrons image). Using the image formed with primary electrons it was possible to determine the pitting nucleation sites, as shown in Fig. 5, where two pitting nuclei are localized inside the austenite. In the solution annealed alloys the pits were found in three different locations: austenite, ferrite and the interface austenite/ferrite; the Table 12 gives for the three above

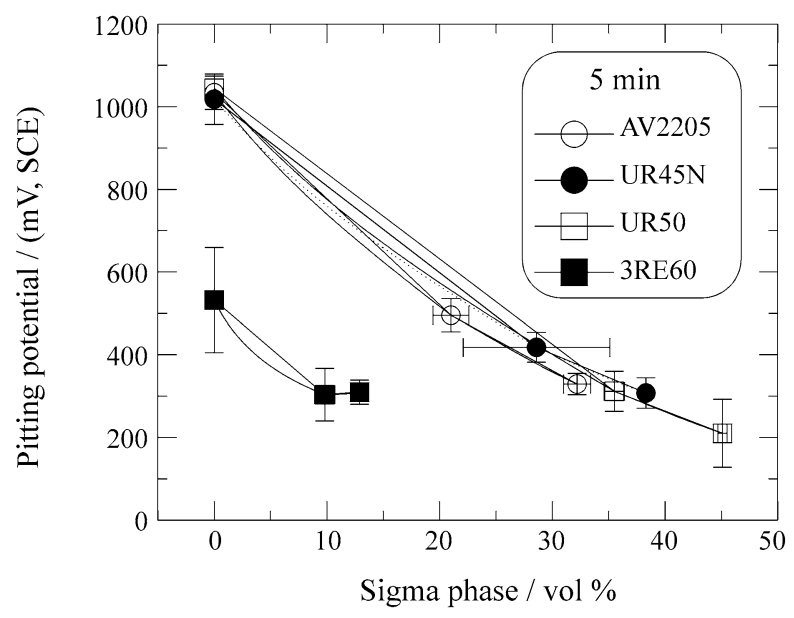

Figure 3. The pitting potential variation with the sigma phase volumetric percentage. The pitting potential was determined in $3.5 \% \mathrm{NaCl}$ aqueous solution with a scanning rate of $1 \mathrm{mV} / \mathrm{s}$ started $5 \mathrm{~min}$ after the immersion of the sample inside the solution. 
alloys the nucleation percentage in each one of these locations.

As can be noticed on Fig. 6 (secondary electrons image) at the 3RE60 alloy the pits are much larger. Using the primary electrons image (Fig. 7) it is observed that the localized corrosion takes place exclusively over the austenite, showing a great facility for nucleation, with several corrosion nuclei over the same austenitic lamella.

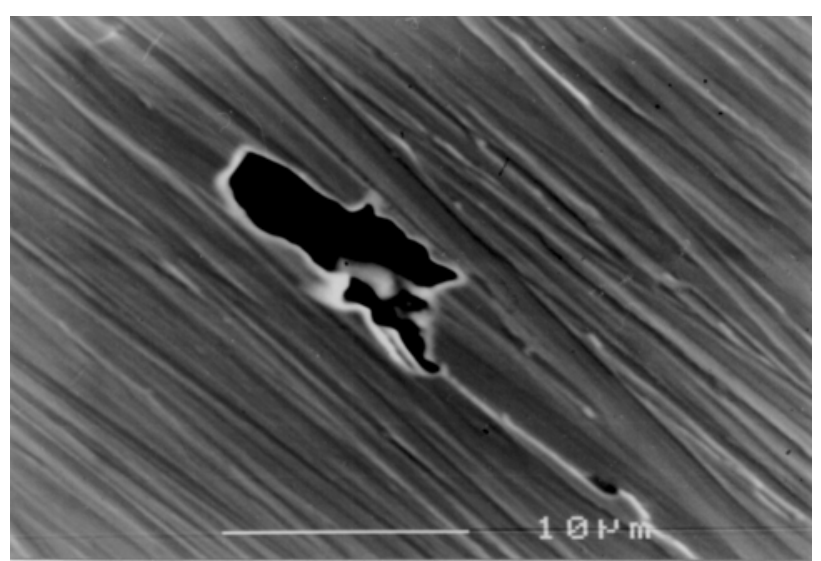

Figure 4. Corrosion pit formed on solution annealed AV2205 alloy after the cyclic potentiodynamic polarization test. SEM - secondary electrons image. 3000X.

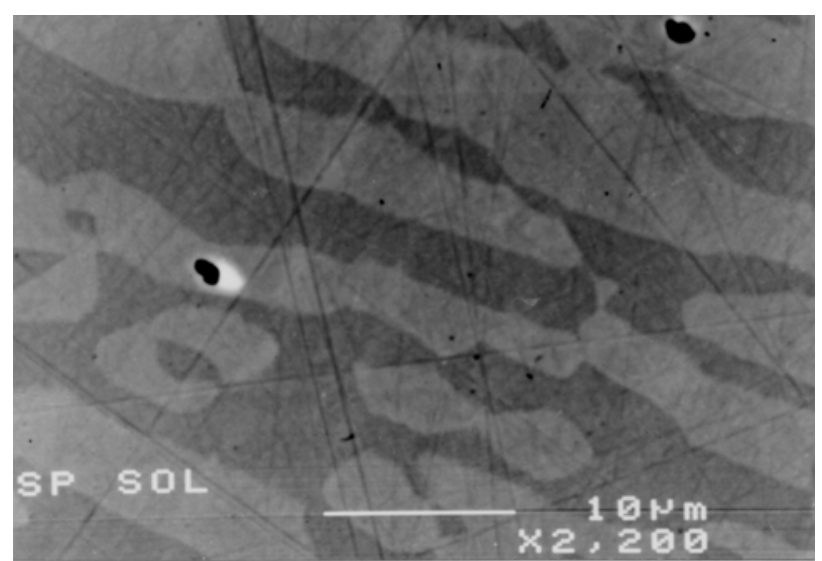

Figure 5. Corrosion pits (black spots) nucleated on austenite of the solution annealed AV2205 alloy after the cyclic potentiodynamic polarization test. SEM - primary electrons image. 2200X.

Table 12. The pitting percentage in three different locations, for the four solution annealed alloys.

\begin{tabular}{lccc}
\hline \multirow{2}{*}{ Alloys } & \multicolumn{3}{c}{ Pits $(\%)$} \\
\cline { 2 - 4 } & Ferrite $(\alpha)$ & Austenite $(\gamma)$ & Interface $(\alpha / \gamma)$ \\
\hline AV2205 & 11 & 44 & 44 \\
UR45N & 19 & 45 & 36 \\
UR50 & 14 & 23 & 63 \\
3RE60 & - & 100 & sporadic \\
\hline
\end{tabular}

The typical aspect of the corroded surface of all alloys after the sigma phase precipitation is shown in Fig. 8. It is noticed that there is a very large facility for nucleation of localized corrosion because the corroded area is very large when compared with that of solution annealed condition. Moreover, it is also observed that the corrosion follows preferential paths. An analysis of the primary electrons images, shown in Fig. 9, indicates that the corrosion followed exclusively two paths: the sigma/austenite interface and the austenite/ferrite interface. Most of the corrosion followed the first path.

\section{Discussion}

The experimental results did show that the presence of sigma phase is very detrimental to the corrosion resistance of duplex stainless steels, as can be realized by the pitting potential results and by the aspect of the corroded surfaces. It was found also that the corrosion was preferentially of the localized type at the austenite/sigma interface. In order to understand the reasons for this behavior it is essential to

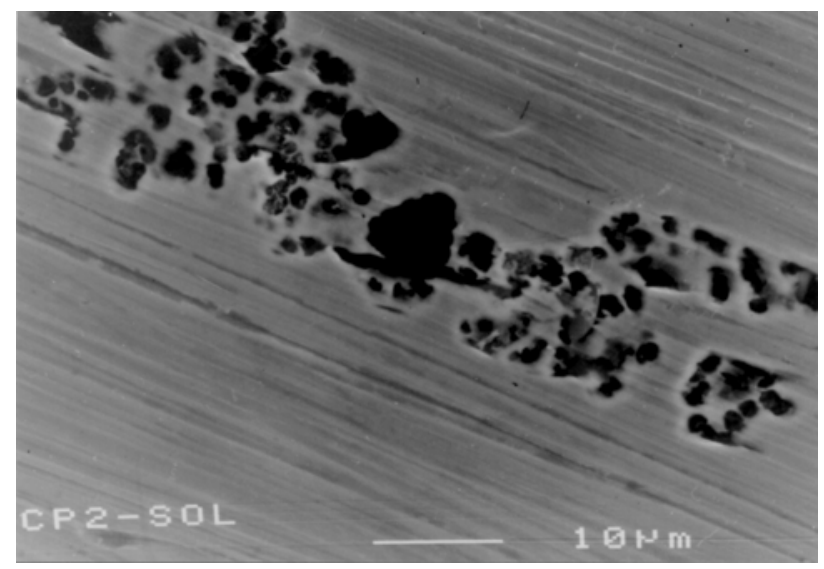

Figure 6. Localized corrosion on solution annealed 3RE60 alloy after the cyclic potentiodynamic polarization test. SEM - secondary electrons image. 3000X.

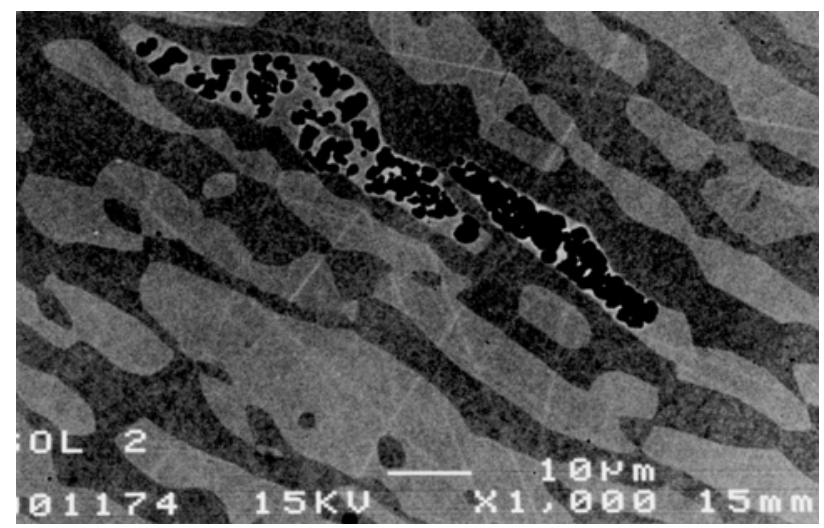

Figure 7. Localized corrosion (black spots) on austenite of the solution annealed 3RE605 alloy after the cyclic potentiodynamic polarization test. SEM - primary electrons image. $3000 X$. 

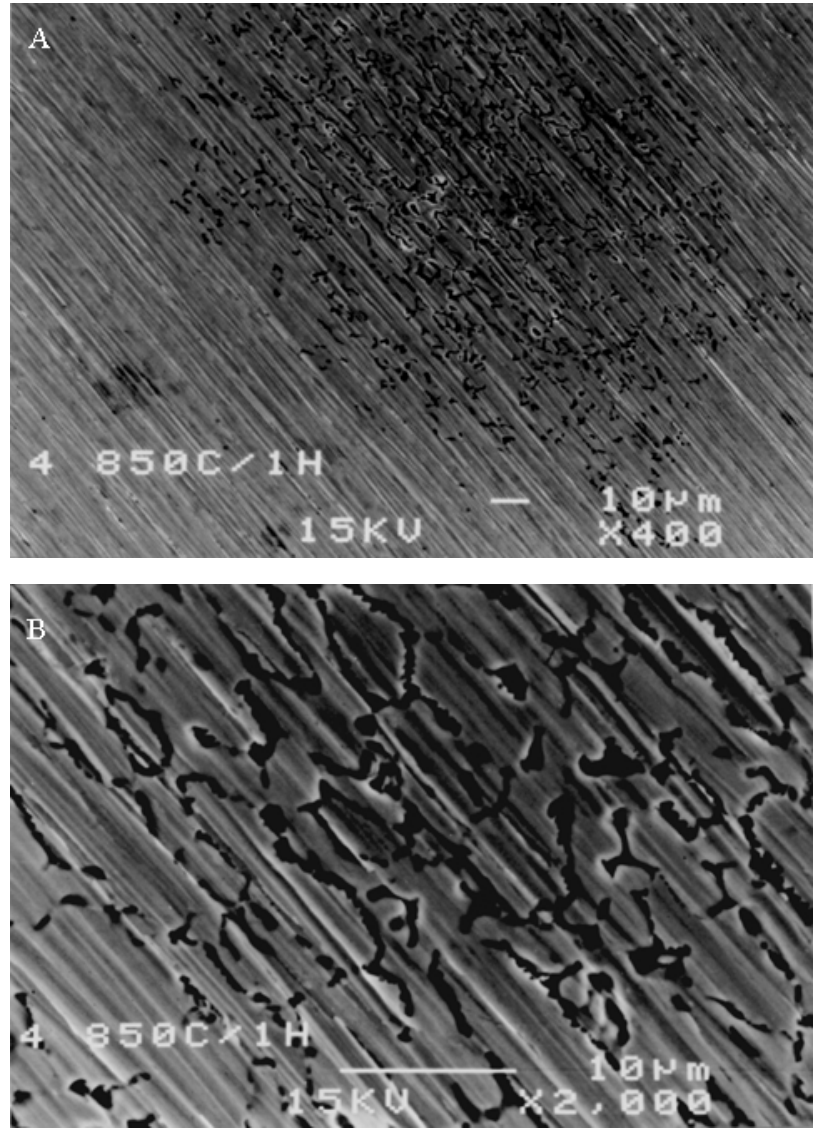

Figure 8. Corroded area of about $150 \mu \mathrm{m}$ (A) of the heat-treated UR45N alloy at $850^{\circ} \mathrm{C} / 1 \mathrm{~h}$ after the cyclic potentiodynamic test, which resembles an intergranular attack. SEM - secondary electrons image. 400X; (B) 2000X (detail of A).

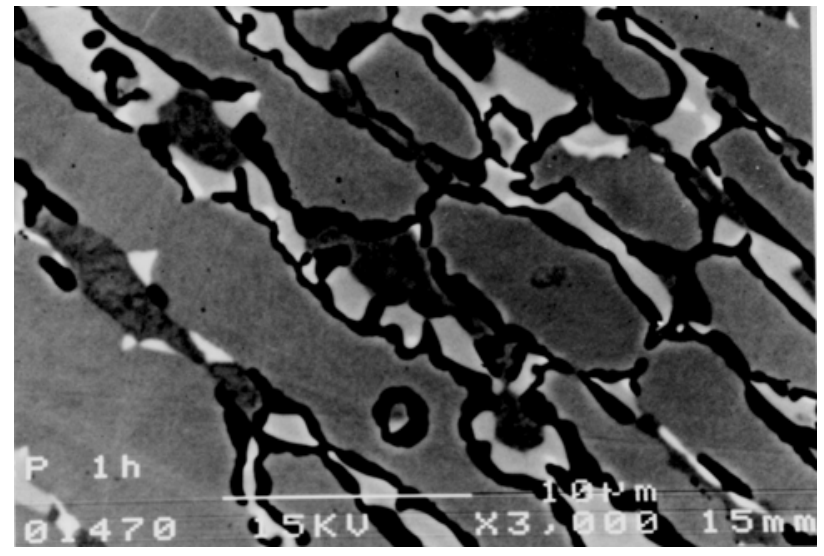

Figure 9. Localized corrosion along the sigma/austenite interface (continuous black strips) on the heat-treated AV2205 alloy at $850^{\circ} \mathrm{C} / 1 \mathrm{~h}$ after the cyclic potentiodynamic test. SEM - primary electrons image. 3000X.

have a good knowledge of the sigma phase precipitation mechanism.

As was already mentioned, the sigma phase precipitation is determined by an euctetoid reaction in which the ferrite is transformed into sigma and ferrite [Eq. (1)]. According to Barbosa et al..$^{7}$ up to $800{ }^{\circ} \mathrm{C}$ the euctetoid is lamellar, while above this temperature, around $900{ }^{\circ} \mathrm{C}$, the sigma phase precipitates in a massive form, leading to a structure named as "divorced euctetoid". In present investigation the latter was the predominant type of sigma phase precipitation.

When a lamellar structure is formed, the growth of the sigma and the austenite phases is cooperative. This happens because during the growth of austenite, which contains less $\mathrm{Cr}$ and Mo than the sigma phase, these elements are expelled to the side so as to assist the sigma phase growth, and at the same time the sigma phase expels $\mathrm{Ni}$ so as to assist the austenite growth. In this way the austenite and the sigma phases are formed side by side, creating the lamellar structure. As the temperature increases, the distance through which these elements diffuse becomes larger and, consequently, the lamellae also become larger. In sufficiently high temperatures, due to a lower thermodynamic potential, there will be a larger difficulty to form new surfaces, and since the diffusion distance is also large, there is no formation of lamellae. Instead the "divorced" structure is formed, that is, there is no cooperative growth and the phases are separated into massive forms.

In this way, after the sigma phase precipitation the structure of the four alloys has four phases with different corrosion resistance, three of them having high $\mathrm{Cr}$ and $\mathrm{Mo}$ content (the sigma phase, the ferrite and the initial austenite) and the fourth, the new austenite, being essentially a Fe-Ni alloy. Since the corrosion resistance is strongly dependent on $\mathrm{Cr}$ and Mo content, it becomes clear why the localized corrosion takes place at the austenite/sigma interface, which is the place where the low corrosion resistant new austenite is located.

Although the corrosion resistance evaluation was undertaken with a technique that determines the pitting corrosion resistance, the corrosion morphology observed on alloys with the sigma phase and on solution annealed alloy 3RE60 is not typical of pitting corrosion. It is rather representative of a selective corrosion of a non-corrosion resistant phase, set up by its chemical composition.

\section{Conclusions}

The precipitation of sigma phase in duplex stainless steels makes them highly susceptible to localized corrosion at the interface between the sigma phase and the austenite.

The performed calculations indicate that during the euctetoid decomposition of ferrite a divorced austenite lamella is formed at the sigma/austenite interface, which is Mo free and whose $\mathrm{Cr}$ content is very low. There will be no difficulty then to breakdown the passive film of this lamella, allowing a selective corrosion of this phase to proceed easily. 


\section{References}

1.Bain, E.C.; Griffiths, W.E. Am. Inst. Min. Metall. Eng., v. 75, p. 166-211, 1927.

2.Hall, E.O.; Algie, S.H. Metallurgical Reviews, v. 11, p. 61-88, 1966.

3. Gordon, G.M. Stress Corrosion Cracking and Hydrogen Embrittlement of Iron Base Alloys, ed. Staehle, R. W. NACE, Houston, TX, USA, p. 893-945, 1977.

4. DeBold, T.A. J. Metals, n. 3, p. 12-15, 1989.

5. Brandi, S.D.; Padilha, A.F. Proceedings of $2^{\text {nd }}$ Brazilian Seminar on Stainless Steels - INOX 90. ABM, São Paulo, SP, Brazil, p. 135-152, 1990 (in Portuguese).

6. Maehara, Y.; Koike, M.; Jujiro, N.; Kunitake, T. Trans. Iron Steel Japan, v. 23, n. 3, p. 240-246, 1983.

7. Barbosa, C.A.; Mori, F.Y.; Souza, M.H.C.; Falleiros, I.G.S. Metalurgia-ABM, v. 32, n. 227, p. 669-673, 1976 (in Portuguese).

8. Norström, L.A.; Petterson, S.; Nordini, S. Zeitsch. Werkstoff Tech., v. 12, p. 229-234, 1981.

9. Maehara, Y.; Ohmori, Y.; Murayama, J.; Jujino, N.; Kunitake, T. Metal Science, v. 17, n. 11, p. 541-547, 1983.

10. Hideaki, M.; Kudo, T.; Koso, M.; Miura, M.; Moroishi, T. Duplex Stainless Steel, ed. Lula, R.A. ASM, Metals Park, OH, USA, p. 95-112, 1983.

11. Truman, J.E.; Pirt, K.R. Duplex Stainless Steel, ed. Lula, R.A. ASM, Metals Park, OH, USA, p. 113-142, 1983.
12. Potgieter, J.H. Br. Corrosion J., v. 27, n. 3, p. 219-232, 1992.

13. Francis, R. Br. Corrosion J., v. 27, n. 4, p. 319-320, 1992.

14. Nilsson, J.O.; Wilson A. Mater. Sci. Technol., v. 9, n. 7, p. 545-554, 1993.

15. Kuroda, T.; Matsuda, F. Trans. JWRI, v. 23, n. 2, p. 205-211, 1994.

16. Ravindranath, K.; Malhotra, S.N. Corrosion, v. 50, n. 4, p. 318-328, 1994.

17. Wilms, M.E.; Gadjil, V.J.; Krougman, J.M.; Ijsseling, F.P. Corros. Sci., v. 36, n. 5, p. 871-881, 1994.

18. Ravindranath, K.; Malhotra, S.N. Corros. Sci., v. 37, n. 1, p. 121-132, 1995.

19. Adhe, K.N.; Kain, V.; Madangopal, K.; Gadiyar, H.S. J. Materials Engineering and Performance, v. 5, n. 4, p. 500-506, 1996.

20. Lopez, N.; Cid, M.; Puiggali, M.; Azkarate, I.; Pelayo, A. Materials Science and Engineering A, v. A229, n. 1-2, p. 123-128, 1997.

21. Egan, F. Stainless Steel World, v. 9, n. 10, p. 61-63, 65, 1997.

22. Gunn, R.N. TWI Journal, v. 7, n. 1, p. 5-45, 1998.

23. Metals Handbook, 9 ed., ASM, Metals Park, OH, USA, v. 3, p.34, 1987. 